\title{
Effect of variation in coronary artery anatomy on distribution of stenotic lesions
}

\author{
STEPHEN SALTISSI, MICHAEL M. WEBB-PEPLOE, AND \\ D. JOHN COLTART
}

From the Department of Cardiology, St. Thomas' Hospital, London

SUMMARY A relation between the proximal or distal localisation of atherosclerotic lesions and 3 anatomical variables (i) the length of the left main coronary artery, (ii) its angle of bifurcation into anterior descending and circumflex arteries, and (iii) the dominant coronary artery, was sought at coronary angiography. Studies were made on 149 angiograms of which 95 had critical stenoses $(\geq 50 \%$ of vessel lumen) and the remaining 54 were either normal or contained only minimal disease.

The mean left main coronary artery length was shorter in the patients with coronary artery disease $(10.6 \mathrm{~mm})$ than in the normals $(12.9 \mathrm{~mm})$. Patients with proximal coronary artery disease $(9.1 \mathrm{~mm})$ had a much shorter mean left main coronary artery length than those with distal lesions alone $(12.9 \mathrm{~mm})$. This finding implies that a short left main coronary artery favours the proximal localisation of atherosclerotic stenoses by increasing the severity of atherogenesis proximally.

No significant difference was found between the mean angle of bifurcation of the normals $\left(75^{\circ}\right)$ and that of the total coronary artery disease group $\left(81^{\circ}\right)$. The patients with proximal disease showed a tendency towards a wider bifurcation angle $\left(85^{\circ}\right)$ than the distal disease group $\left(76^{\circ}\right)$ but this did not reach significance at the 5 per cent level.

When present in combination with a short left main coronary artery, a wide bifurcation angle was associated with a trend towards proximal localisation of stenoses over and above that of a short left main coronary artery alone.

Dominant circumflex systems had significantly shorter mean left main coronary artery lengths $(9.1 \mathrm{~mm})$ than had dominant right coronary arteries $(12.0 \mathrm{~mm})$. No effect of circumflex dominance on localisation of disease was found.

These results show that a short left main coronary artery alone constitutes an anatomical factor which favours proximal localisation of stenoses. This effect is further enhanced by its combination with a wide angle of bifurcation.

The distribution of atherosclerotic lesions has been shown both in animals (Flaherty et al., 1972) and in man (Mishkin, 1967; Montenegro and Eggen, 1968) to be patchy but non-random, with stenoses being situated preferentially at branch ostia, at bifurcations, and in the proximal segments of the resulting daughter vessels. This study investigates the relation of 3 aspects of coronary artery anatomy (length of left main coronary artery; its angle of bifurcation into the left anterior descending and circumflex branches; and the dominance or otherwise of the circumflex artery) to the incidence of proximal stenoses. In view of the poor prognosis of proximal lesions and their suitability for bypass

Received for publication 14 February 1979 grafting (Johnson and Kayser, 1973; Takaro et al., 1976), the discovery of innate anatomical risk factors which favour their formation is of importance.

\section{Patients and methods}

Assessments were made of 161 consecutive coronary angiograms carried out at St. Thomas' Hospital by the Judkins technique. Of these, 7 were excluded as technically unacceptable and the remaining 154 comprised the study group. In a further 5 angiograms only one view of the left main coronary artery was taken and these were not included in that part of the study relating to length of left main coronary artery which was therefore based on 149 angiograms. Of these, 54 were normal or had 


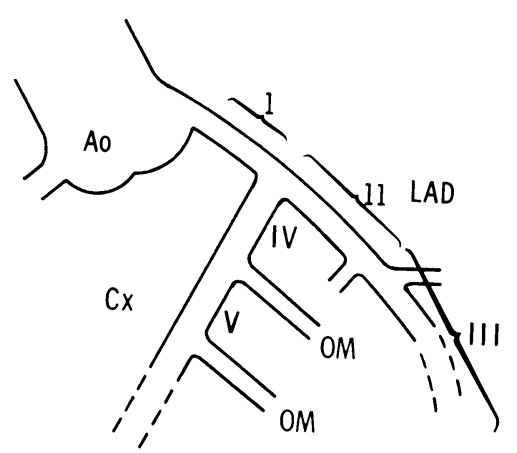

Fig. 1 Segmentation of left coronary artery. Schematic diagram of left main coronary artery and its bifurcation into left anterior descending and circumflex arteries, displaying the extent and distribution of segments. Ao, aorta; LAD, left anterior descending artery; $C x$, left circumflex artery; OM, obtuse marginal artery; Seg I, L mainstem; II, LAD proximal to first septal; III, distal $L A D ; I V, C x$ proximal to first $O M ; V$, distal $C x$. minimal disease only and constituted a control group.

The left mainstem length was measured in each case from its orifice (visualised by spillback of contrast medium into the aorta during selective injection) to its bifurcation into the left anterior descending and circumflex arteries. Measurements were made in the most appropriate single frame in both the right anterior oblique and left anterior oblique projections in all patients. Correction for magnification was made by calculating the ratio of the projected diameter of the Judkins catheter to its actual diameter (from the manufacturer's data). The measured left main coronary artery lengths were then divided by this ratio and the longest corrected measurement in either the right anterior oblique or left anterior oblique views was taken as the true left main coronary artery length. In 63 patients a left cranio-caudal view was also available and the left main coronary artery length obtained in these was compared with the longer value from either the right anterior oblique or left anterior oblique view.

Each left coronary artery was divided into 5 segments (see Fig. 1). The severity of all atheromatous lesions was assessed and their distribution in these segments noted. A lesion was deemed critical if it reduced the measured luminal diameter

Table 1 Mean left main coronary artery length in relation to presence and site of coronary artery disease

\begin{tabular}{lllll}
\hline & & $\begin{array}{l}\text { All } \\
\text { coronary } \\
\text { artery } \\
\text { disease } \\
\text { patients }\end{array}$ & $\begin{array}{l}\text { Prox. } \\
\text { coronary } \\
\text { artery } \\
\text { disease } \\
\text { patients }\end{array}$ & $\begin{array}{l}\text { Non-prox. } \\
\text { coronary } \\
\text { artery } \\
\text { disease } \\
\text { patients } \\
\text { patients }\end{array}$ \\
\hline $\begin{array}{l}\text { Number of cases } \\
\begin{array}{l}\text { Mean left main } \\
\text { coronary artery } \\
\text { (mm) }\end{array}\end{array}$ & 54 & 95 & 56 & 39 \\
\begin{tabular}{l} 
P value \\
\hline
\end{tabular} & 12.9 & 10.6 & 9.1 & 12.9 \\
\hline
\end{tabular}

by 50 per cent or more in 2 views when compared with the diameter of the contiguous normal vessel lumen. Such lesions located in segments I, II, and IV were considered proximal and those in segments III and V distal.

The projected radiological angle between the origins of the left anterior descending and circumflex arteries (bifurcation angle) was measured with a protractor in the right anterior oblique view. The dominant coronary artery (either right coronary artery or circumflex) was defined as the vessel supplying either the atrioventricular node branch or the posterior descending artery if the former was not discernible and was noted in each case.

In order to assess the influence of the combination of left main coronary artery length and bifurcation angle on the proximal localisation of disease, the angiograms were divided into those with a short left main coronary artery (less than the mean length of $10.6 \mathrm{~mm}$ for the coronary artery disease group) and those with a long left main coronary artery $(>10.6 \mathrm{~mm})$. The groups so formed were then subdivided according to the presence of a wide bifurcation angle (greater than the mean angle of $81^{\circ}$ for the coronary artery disease group) or a narrow one $\left(<81^{\circ}\right)$. The distribution of stenoses in each of the 4 resulting subgroups was noted (see Table 3).

Table 2 Mean bifurcation angle in relation to presence and site of coronary artery disease

\begin{tabular}{|c|c|c|c|c|}
\hline & $\begin{array}{l}\text { All } \\
\text { normal } \\
\text { patients }\end{array}$ & $\begin{array}{l}\text { All } \\
\text { coronary } \\
\text { artery } \\
\text { disease } \\
\text { patients }\end{array}$ & $\begin{array}{l}\text { Prox. } \\
\text { coronary } \\
\text { artery } \\
\text { disease } \\
\text { patients }\end{array}$ & $\begin{array}{l}\text { Non-prox. } \\
\text { coronary } \\
\text { artery } \\
\text { disease } \\
\text { patients }\end{array}$ \\
\hline Numbers & 54 & 92 & 53 & 39 \\
\hline $\begin{array}{l}\text { Mean bifurcation } \\
\text { angle }\end{array}$ & ${ }^{75^{\circ}}$ & $81^{\circ}$ & $1^{85^{\circ}}$ & $\begin{array}{c}76^{\circ} \\
1\end{array}$ \\
\hline$P$ value & $<0.1$ & & $0.05<\mathrm{F}$ & \\
\hline
\end{tabular}


Table 3 Site of coronary artery disease in relation to various combinations of left main coronary artery length and angle of bifurcation

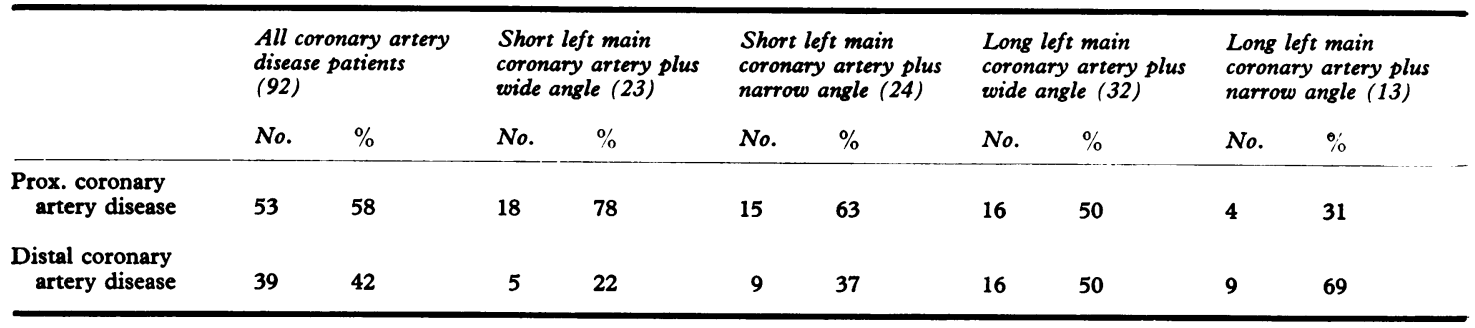

\section{Statistical analysis}

The results were analysed using the test for the significance of the difference between the means of 2 large samples or a $\chi^{2}$ test combining $2 \times 2$ tables when necessary.

\section{Results}

Of the 149 angiograms studied, 95 showed critical stenoses of which $56(59 \%)$ were proximal and 39 $(41 \%)$ were distal. The remaining 54 angiograms were either normal or had non-critical minor disease only.

\section{(a) LENGTH OF LEFT MAIN CORONARY} ARTERY

The mean lengths of the left main coronary arteries in relation to the presence and site of coronary artery disease are shown in Table 1 . The mean length in the 95 patients with coronary artery disease was $10.6 \mathrm{~mm}$ which was significantly shorter $(P<0.05)$ than that of the normals $(12.9$ $\mathrm{mm})$. The group with proximal lesions had much shorter $(P<0.005)$ left main coronary arteries $(9.1 \mathrm{~mm})$ than those with distal lesions alone $(12.9 \mathrm{~mm})$.
The frequency distribution of left main coronary artery lengths is displayed in Fig. 2 which contrasts the patients with proximal disease with those having distal lesions. This distribution is bimodal. The patients with coronary artery disease predominantly have shorter left main coronary arteries ( 8 to 10 $\mathrm{mm}$ ) than the patients with distal coronary artery disease who form a separate group with longer left main coronary arteries (12 to $14 \mathrm{~mm}$ ). An immediate bifurcation was found radiologically in 8.4 per cent of cases. This contrasts with the pathological study of Penther et al. (1977) in which no case of immediate bifurcation was found.

\section{(b) ANGLE OF BIFURCATION}

All of the 54 control angiograms and 92 of the 95 critically diseased angiograms had measurable bifurcation angles in the right anterior oblique projection. The mean angles found in relation to the presence and site of coronary artery disease are shown in Table 2. The difference between the mean bifurcation angle in the normals $\left(75^{\circ}\right)$ and the total coronary artery disease group $\left(81^{\circ}\right)$ was not significant $(P>0 \cdot 1)$. However, the mean angle in the patients with proximal disease $\left(85^{\circ}\right)$ was wider than that in the group with distal stenoses alone $\left(76^{\circ}\right)$ though the difference did not reach significance at the 5 per cent level $(0.05<P<0 \cdot 1)$.

PROXIMAL CAD PRESENT

DISTAL CAD PRESENT

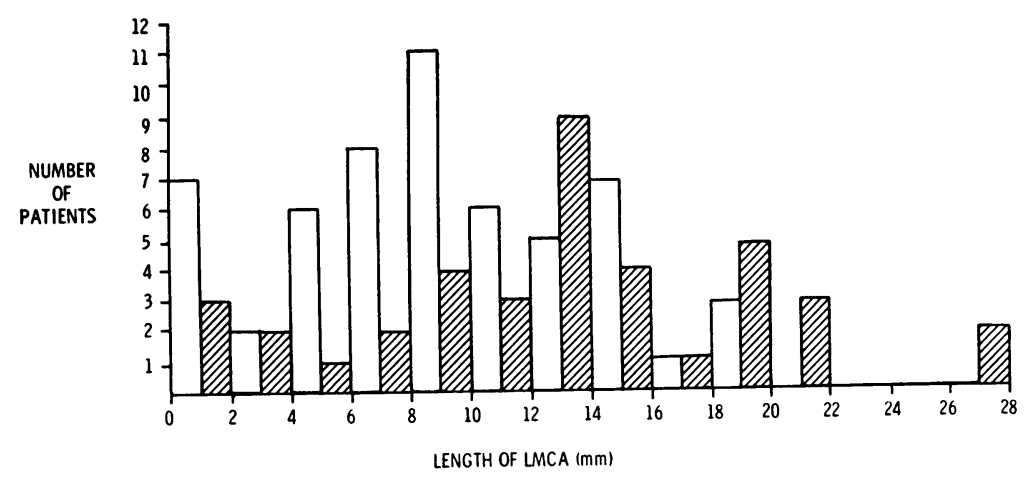

Fig. 2 Length of left main coronary artery in 95 patients with coronary artery diseasecomparison between vessels with proximal and distal disease showing bimodal distribution. 
(c) COMBINATION OF LEFT MAIN CORONARY ARTERY LENGTH AND BIFURCATION ANGLE

The site of coronary artery disease in relation to the various combinations of left main coronary artery length and bifurcation angle is shown in Table 3. This shows that the greatest proximal localisation of stenoses $(78 \%)$ was found when a combination of a short left main coronary artery with a wide bifurcation angle existed, and the tendency toward proximal distribution was slightly greater for this combination than for a short left main coronary artery alone $(0.05<P<0 \cdot 1)$.

\section{(d) ARTERY OF DOMINANCE}

Of the 149 patients studied, 23 (15\%) had a dominant circumflex artery and in this group the mean left main coronary artery was $9.1 \mathrm{~mm}$. This was significantly shorter $(P<0.05)$ than in the 126 patients with a dominant right coronary artery (or mixed dominance) $12.0 \mathrm{~mm}$. Among the group with coronary artery disease, no difference in the prevalence of proximal lesions was found between those with a dominant circumflex (9 out of 15, $60 \%$ ) and those without (47 out of $80,59 \%$ ).

(e) COMPARISON OF LEFT MAIN CORONARY ARTERY LENGTH IN DIFFERENT VIEWS

In the 64 angiograms having right anterior oblique, left anterior oblique, and left cranio-caudal views, the mean left main coronary artery length in the left cranio-caudal projection was $12.2 \mathrm{~mm}$ which did not differ significantly $(P>0 \cdot 1)$ from that based on the longer of the other two views $(10.8 \mathrm{~mm})$.

\section{Discussion}

Atherosclerosis is not randomly distributed in the coronary arteries. Montenegro and Eggan (1968) in a series of 27207 coronary arterial trees showed a much greater prevalence of stenoses in the proximal arterial segments. The peak incidence was in the first and second centimetres of the left anterior descending circumflex, and the second to third centimetres of the right coronary artery. The finding in this study that 59 per cent of lesions were proximal is in agreement with this. The mechanisms that produce this tendency to proximal distribution of atherosclerosis are not known. Haemodynamic factors, however, may be important (Blumenthal, 1967; Stehbens, 1975), especially changes in arterial wall shear stress which is proportional to flow rate. Caro et al. (1969) and Caro (1973) implicate regions of low wall shear which they suggest retard the efflux of intramurally synthesised lipid from the arterial wall into the blood stream. Fry $(1968,1973)$ reaches the opposite conclusion and regards areas of high wall shear as atherogenic. This author feels

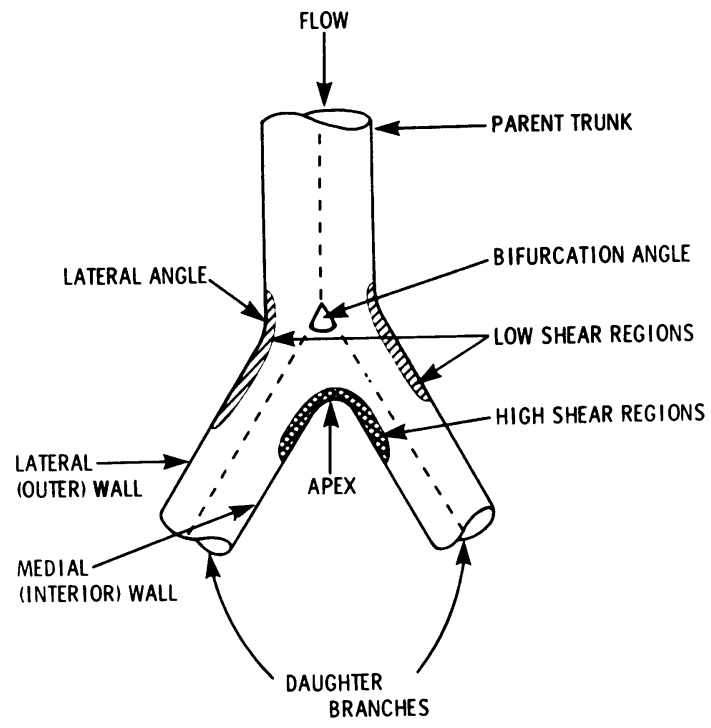

Fig. 3 Distribution of high and low shear regions at a bifurcation and in the proximal daughter branches created by incident flow.

that high wall shear results in (i) damage to endothelial cells thus increasing their permeability to proteins and lipoproteins, and (ii) structural changes including intimal fibrosis, smooth muscle cell proliferation, and endothelial cell erosion with an associated exaggerated reparative process. Clearly defined regions of high and low wall shear stress (often with a sharp boundary between them) are created at the apex of bifurcations and in the proximal few centimetres of the resulting daughter branches (Brech and Bellhouse, 1973; Malcolm and Roach, in press) (Fig. 3). The length of the left main coronary artery and the angle of bifurcation are anatomical variables which alter haemodynamics and hence may affect distribution of atherosclerotic stenoses.

The mean left main coronary artery length has been estimated at angiography and necropsy in a number of reports (see Table 4). A previous

Table 4 Left main coronary artery length in previous studies

\begin{tabular}{lcll} 
Type of study & $\begin{array}{c}\text { Mean left main } \\
\text { coronary artery } \\
\text { length }(\mathrm{mm})\end{array}$ & Authors \\
\hline Angiographic & 9.5 & Fox et al. (1973) \\
& 10.4 & Kronzon et al. (1974) \\
& $12 \cdot 0$ & Furlong et al. (1972) \\
& $12 \cdot 8$ & Lewis et al. (1970) \\
& 12.4 & Gazetopoulos et al. (1976) \\
Pathological & 10.36 & Penther et al. (1977) \\
& 11.4 & Green et al. (1967) \\
& 13.5 & Baroldi and Scomazzoni (1967) \\
& 5.5 & Fox et al. (1973) \\
\hline
\end{tabular}


angiographic study (Gazetopoulos et al., 1976) based on a relatively small sample (43 patients) found a shorter mean left main coronary artery length in arteries with atheromatous lesions-but made no distinction between those with proximal and distal disease. A more recent anatomical study (Penther et al., 1977) found no such relation. The present study shows that the mean left main coronary artery length is much shorter $(9.1 \mathrm{~mm})$ when proximal disease is present than when distal disease alone exists $(12.9 \mathrm{~mm})$. This implies that a short left main coronary artery favours the proximal localisation of atherosclerotic lesions. The relatively poor prognosis of such lesions and their apparent benefit from bypass grafting (Johnson and Kayser, 1973; Takaro et al., 1976) make this relation important.

Two complementary mechanisms probably underlie this relation. Firstly, by Poiseuille's equation, the length of a rigid pipe through which a Newtonian fluid flows is directly proportional to the pressure drop in the pipe and inversely related to the volume flow along it. Consequently, the shorter the pipe the smaller the pressure drop and the larger the flow. However, the application of this equation to flow in human blood vessels has certain limitations since blood is a non-Newtonian fluid and the vessels are non-rigid (distensible). None the less, within the physiological range in vessels greater than $0.1 \mathrm{~cm}$ internal diameter, blood behaves to a large extent in a Newtonian fashion (Haynes and Burton, 1959; McDonald, 1974), and these relations hold good. Thus a short left main coronary artery results in a small pressure drop and a large flow at the bifurcation. The resulting high wall shear favours atherogenesis (Fry, 1968) at the bifurcation and in the proximal segments of the daughter branches (left anterior descending and circumflex). A long left main coronary artery has the opposite effect and causes increased pressure drop, reduced flow, and hence low wall shear at the bifurcation. This may be protective against atheroma formation.

Secondly, Tjotta (1963), Nordenström (1966), and Gazetopoulos et al. (1976) have pointed out that lesions localise in areas of systolic kinking and motion. The proximal segments of the left anterior descending and circumflex are relatively untethered and hence prone to excess systolic bending. In addition, their lengths are inversely proportional to the mainstem length. Thus a short left main coronary artery is associated with long untethered proximal segments in the left anterior descending and circumflex which may then be prone to excessive systolic motion and hence to increased risk of atheromatous degeneration.
The importance of the angle of bifurcation in altering haemodynamics and hence atherogenesis has been investigated experimentally (Brech and Bellhouse, 1973; Malcolm and Roach, in press). These latter workers used a family of glass models with bifurcation angles varying from $45^{\circ}$ to $180^{\circ}$. They confirmed the apex and proximal medial wall of the daughter branches as sites of high flow and high shear and the lateral angles as low flow areas of low shear (Fig. 3). At these angles separation of fluid streamlines move away from the lateral walls (boundary layer separation) to leave an underlying space. This separated region contains fluid streamlines reflected from daughter branches. Flow velocity and wall shear are low in this region. Further, they showed that the magnitude of boundary layer separation with its associated low shear separated regions was increased by (a) asymmetry or irregularity of the bifurcation, (b) imbalance of the relative flows down the daughter branches (a common situation in nature), and notably by (c) increasing angle of bifurcation. In addition, turbulence and vortex formation in daughter branches were greater in the models with wider bifurcation angles.

Thus by alteration of local shear forces and turbulence in the proximal daughter branches, especially under conditions of flow imbalance, the angle of bifurcation theoretically exerts an important effect on the localisation of stenoses. In the present study, the mean bifurcation angle was wider in the group with proximal disease $\left(85^{\circ}\right)$ than in the group with distal disease $\left(76^{\circ}\right) \quad(0.05<P<0.1)$ though this did not reach significance at the 5 per cent level. Similarly, in combination with a short left main coronary artery, a wide angle exerted a small additional influence favouring proximal localisation over and above that of a short left main coronary artery alone $(0 \cdot 05<\mathrm{P}<0 \cdot 1)$. The radiologi$\mathrm{cal}$ assessment of the bifurcation angle in the right anterior oblique view did not reflect the true angle since the parent trunk (left main coronary artery) and daughter branches (left anterior descending and circumflex) ran in different planes and the directions often overlapped. These factors reduce the possibility of obtaining a significant association.

The mean left main coronary artery length $(9.1 \mathrm{~mm})$ was significantly shorter $(P<0.05)$ in the group with dominant circumflex arteries than in the right coronary artery group $(12.0 \mathrm{~mm})$. This angiographic finding is in close agreement with that of Kronzon et al. (1974) but contrary to the result of the pathological study of Penther et al. (1977).

Despite the finding of shorter mean left main coronary artery length, dominant circumflex systems were not associated with a higher prevalence of 
proximal disease in this study. The explanation for this may lie in the small sample size ( 15 patients with coronary artery disease and a dominant circumflex artery). Alternatively, an effect of this configuration negating the influence of a short left main coronary artery and hence protecting against proximal distribution of disease could be postulated. This, however, would be contrary to the angiographic findings of Gensini and Buonanino (1968) that lesions in the circumflex artery were more frequent and severe when it was dominant.

Thus coronary artery anatomy may play an important role in the pathogenesis and localisation of demonstrated lesions. In addition, the rate of progression of proximal disease may be strongly influenced by anatomical characteristics of the coronary arteries. Angiographic definition of this anatomy may prove predictive of an enhanced rate of proximal progression of lesions by showing a configuration favouring further proximal disease.

\section{References}

Baroldi, G., and Scomazzoni, G. (1967). Coronary Circulation in the Normal and Pathological Heart, pp. 9 and 35. Armed Forces Institute of Pathology, Washington, DC.

Blumenthal, H. T. (1967). Haemodynamic factors in the etiology of arteriosclerosis. In Cowdry's Arteriosclerosis : a Survey of the Problem, 2nd edn, pp. 329-362, ed H. T. Blumenthal. Charles C. Thomas, Springfield, Illinois..

Brech, R., and Bellhouse, B. J. (1973). Flow in branching vessels. Cardiovascular Research, 7, 593-600.

Caro, C. G. (1973). Transport of material between blood and wall in arteries. In Atherogenesis: Initiating Factors, Ciba Foundation Symposium No. 12, pp. 127-164. Associated Scientific Publishers, Amsterdam.

Caro, C. G., Fitzgerald, J. M., and Schroter, R. C. (1969). Arterial wall shear and distribution of early atheroma in man. Nature, 223, 1159-1161.

Flaherty, J. T., Ferrans, V. J., Pierce, J. E., Carew, T. E., and Fry, D. L. (1972). Localising factors in experimental atherocsclerosis. In Atherosclerosis and Coronary Heart Disease, pp. 40-83, ed W. Likoff, B. L. Segal, W. Insull, jun, and J. H. Mayer. Grune and Stratton, New York.

Fox, C., Davies, M. J., and Webb-Peploe, M. M. (1973). Length of the left main coronary artery. British Heart fournal, 35, 796-798.

Fry, D. L. (1968). Acute vascular endothelial changes associated with increased blood velocity gradients. Circulation Research, 22, 165-197.

Fry, D. L. (1973). Responses of the arterial wall to certain physical factors. In Atherogenesis: Initiating Factors, Ciba Foundation Symposium No. 12, pp. 93-125. Associated Scientific Publishers, Amsterdam.

Furlong, M. B., jun, Gardner, T. J., Gott, V. L., and Hutchings, G. M. (1972). Myocardial infarction compli- cating coronary perfusion during open-heart surgery. Fournal of Thoracic and Cardiovascular Surgery, 63, 185-192.

Gazetopoulos, N., Ioannidis, P. J., Marselos, A., Kelekis, D., Lolas, C., Avgoustakis, D., and Tountas, G. (1976). Length of main left coronary artery in relation to atherosclerosis of its branches. A coronary arteriographic study. British Heart fournal, 38, 180-185.

Gensini, G. G., and Buonanino, C. (1968). Coronary arteriography: a study of 100 cases with angiographically proved coronary artery disease. Diseases of the Chest, 54, 90-99.

Green, G. E., Bernstein, S., and Reppert, E. H. (1967). The length of the left main coronary artery. Surgery, 62, 10211024.

Haynes, R. H., and Burton, A. C. (1959). Role of the nonNewtonian behaviour of blood in haemodynamics. American fournal of Physiology, 197, 943-950.

Johnson, W. D., and Kayser, K. L. (1973). An expanded indication for coronary surgery. Annals of Thoracic Surgery, 16, 1-6.

Kronzon, I., Deutsch, P., and Glassman, E. (1974). Length of the left main coronary artery. American fournal of Cardiology, 34, 787-789.

Lewis, C. M., Dagenais, G. R., Freisinger, G. C., and Ross, R. S. (1970). Coronary arteriographic appearances in patients with left bundle branch block. Circulation, 41, 299-307.

McDonald, D. A. (1974). In Blood Flow in Arteries. Edward Arnold, London.

Malcolm, A. D., and Roach, M. R. Flow disturbances at the apex and lateral angles of a variety of bifurcation models and their role in the development and manifestations of arterial disease. Stroke (in press).

Mishkin, M. (1957). Extracranial ischemic lesions which secondarily involve the brain. Ratiologic Clinics of North America, 5, 395-408.

Montenegro, M. R., and Eggen, D. A. (1968). Topography of atherosclerosis in the coronary arteries. Laboratory Investigation, 18, 126-133.

Nordenström, B. (1966). Mechanical strain on certain sections of the coronary arteries. Investigative Radiology, 1, 306-313.

Penther, P. H., Boschat, J., Morin, J. F., Blanc, J. J., and Granatelli, D. (1977). The length of the left main coronary artery: pathological features. American Heart fournal, 94, 705-709.

Stehbens, W. E. (1975). The role of hemodynamics in the pathogenesis of atherosclerosis. Progress in Cardiovascular Diseases, 18, 89-103.

Takaro, T., Hultgren, H. N., Lipton, M. J., and Detre, K. M. (1976). The VA cooperative randomised study of surgery for coronary occlusive disease. II. Sub-group with significant left main lesions. Circulation, 53 and 54, Suppl. III, 107-117.

Tjotta, E. (1963). The distribution of atheromatosis in the coronary arteries. Fournal of Atherosclerosis Research, 3, 253-261.

Requests for reprints to Dr D. John Coltart, Department of Cardiology, St. Thomas' Hospital, London SE1 7EH. 